\title{
28 Research Square \\ Identification of RPSA as a Potential Biomarker in Bronchoalveolar Lavage Fluid for Acute Respiratory Distress Syndrome
}

\section{Yang Xia}

Anhui Medical University

Lei Gao

Second Affiliated Hospital of Anhui Medical University

Lili Guo

Anhui Medical University

Hao Li

Anhui Medical University

\section{Min Shao}

First Affiliated Hospital of Anhui Medical University

\section{Qigang Yang}

First Affiliated Hospital of Anhui Medical University

Nian Liu

First Affiliated Hospital of Anhui Medical University

\section{Ming Fang}

First Affiliated Hospital of Anhui Medical University

\section{Hui Xu}

Anhui Medical University

Jiajin Li

Anhui Medical University

Hao Gu

Anhui Medical University

Hui Zhao

Second Affiliated Hospital of Anhui Medical University

Gengyun Sun

First Affiliated Hospital of Anhui Medical University

\section{Ling Zhang ( $\nabla$ zhangling8606@163.com )}

The First Affiliated Hospital of Anhui Medical University

\section{Research}


Keywords: RPSA, ARDS, Biomarker, Proteomics, iTRAQ

Posted Date: December 29th, 2021

DOI: https://doi.org/10.21203/rs.3.rs-1190553/v1

License: (c) (1) This work is licensed under a Creative Commons Attribution 4.0 International License. Read Full License 


\section{Abstract}

\section{Background}

Acute respiratory distress syndrome (ARDS) is a life-threatening condition leading to severe pulmonary injuries, and proteomic analysis of bronchoalveolar lavage fluid (BALF) might elucidate potential biomarkers for diagnosis and targets for treatment of ARDS.

\section{Methods}

Through iTRAQ analysis, we investigated paired BALF samples from three ARDS patients in the acute and recovery phases. The proteins sharing the same expression patterns between the two ARDS phases among different patients were determined as co-upregulated and co-downregulated proteins (CUDPs), and differentially expressed proteins (DEPs), whose fold change $>1.2$ and $P$ value $<0.05$, were selected from CUDPs. The Gene Ontology (GO) and Kyoto Encyclopedia of Genes and Genomes (KEGG) analyses were applied to determine the enriched functions and pathways of the CUDPs. Protein-protein interaction (PPI) network was generated at STRING database, and hub genes were identified by the Cytoscape software. A549 cells were treated by lipopolysaccharide (LPS) to simulate alveolar epithelial cells in ARDS.

\section{Results}

We identified 374 CUDPs and 53 DEPs. The GO analysis indicated that the most significantly enriched function was neutrophil mediated immunity response, and the KEGG analysis revealed that the 374 CUDPs were most significantly enriched in Coronavirus disease COVID-19 interaction. RPSA was discovered as the most top hub gene among DEPs, and was downregulated at protein levels during ARDS recovery. Moreover, we further confirmed that both RNA and protein level of RPSA increased upon inflammatory stimulation in vitro.

\section{Conclusion}

Our results proposed RPSA as a candidate for biomarker and therapeutic target of ARDS.

\section{Introduction}

Acute respiratory distress syndrome (ARDS) involves diffuse alveolar damage (DAD) caused by acute and uncontrolled inflammation under the action of multiple internal and external lung injury factors such as severe infection, shock, and trauma[1]. It is a heterogeneous syndrome with complex pathophysiologic mechanisms that endangers human health and with a global incidence of about 3 million people per year, accounting for more than $10 \%$ of the number of patients treated in the ICU[2, 3]. Although the diagnosis and treatment concept and respiratory support strategies of ARDS have been continuously updated and optimized in recent years, there has been no substantial breakthrough or improvement in the overall prognosis of ARDS patients, and the case fatality rate is still $>40 \%[4]$, and even as high as $60 \%$ in one 
study[5]. Therefore, ARDS remains a hot issue in global clinical research. The underlying cellular and molecular mechanisms are unclear, and no targeted drug is available for ARDS treatment.

Proteomics is a powerful approach in life science research to detect protein changes and identify new targets $[6,7]$. Isobaric tags for relative and absolute quantitation (iTRAQ) is one of the new techniques used in modern proteomics, coupling stable isotopes labeling and tandem mass spectrometry to compare the relative amount of proteins from paired samples in a single experiment[8]. The combination of liquid chromatography-tandem mass spectrometry (LC-MS/MS) and ITRAQ is effective and widely used in quantitative proteomics research, with high sensitivity and repeatability[9-11].

The literature suggests that ARDS represents a heterogeneous assemblage of pathophysiological and partially overlapping processes leading to lung injury[12-14]. The 37/67-kDa high-affinity laminin receptor (LAMR1, also known as RPSA) is a non-integrin cell surface receptor for laminin and the main component of the basement membrane. Brassart et al.[15] reported that RPSA was associated with neurodegenerative diseases. Givant-Horwitz et al.[16] found that RPSA is involved in regulating the MAPK signaling pathway. Vania et al.[17] showed that RPSA is involved in maintaining cell viability through apoptotic evasion, allowing tumor progression. RPSA is a complex protein with diverse functions and plays a major role in an inflammatory response, mediating cell adhesion, migration, proliferation, and survival[18-20].

Overall, the analysis of the proteomic changes behind ARDS and RPSA has not been reported. Therefore, this study aimed to examine the proteomics of ARDS using iTRAQ. This work might lead to a more comprehensive understanding of the mechanisms underlying ARDS and the discovery of new pathways and molecules that can be used clinically.

\section{Materials And Methods}

\section{Patients and sample collection}

From the perspective of the clinical outcomes, this study examined three pairs of BALF samples from patients diagnosed with ARDS type I in the acute and recovery phases (Table 1). The BALF samples of acute inflammation-phase and the hyperplasia recovery-phase ARDS were obtained from clinically indicated bronchoscopies with excess material made available for the study. BAL $(100 \mathrm{ml}$ of normal saline) was performed using a standard protocol in either the right middle lobe or left upper lobe (lingual). For this study, the patients were grouped based on the timing of the bronchoscopy: conducted in either the acute inflammation phase of ARDS (days 1-3) or the recovery phase (days 4-8), referenced to the initiation of mechanical ventilation (designated day 1 ). The APACHE-II scores were calculated to assess the severity of illness on the day of bronchoscopy for patients with ARDS, as previously described[21].

\section{Protein extraction and quality control}


Figure 1 shows the framework of this study. The high abundance proteins were removed using the Proteominer kit (Bio-Rad, Hercules, CA, USA). The proteins were reduced and alkylated with $10 \mathrm{mM}$ dithiothreitol (DTT) and $55 \mathrm{mM}$ iodoacetamide (IAM) followed by precipitation with five volumes of cold acetone at $-20^{\circ} \mathrm{C}$ for $\geq 2 \mathrm{~h}$. After sonication, the samples were centrifuged at $25,000 \times \mathrm{g}$ for $15 \mathrm{~min}$ at $4^{\circ} \mathrm{C}$ to remove debris. The protein concentration was determined using the Bradford assay. Proteins $(10 \mu \mathrm{g})$ were mixed with loading buffer, heated at $95^{\circ} \mathrm{C}$ for $5 \mathrm{~min}$, centrifuged at 25,000 $\mathrm{xg}$ for $5 \mathrm{~min}$, and were separated by $12 \%$ SDS polyacrylamide gel. After electrophoresis, the gel was stained and de-stained by a protein staining instrument for $10 \mathrm{~min}$. The images were scanned. Dyeing and stripping instrument: L00657C, Genscript, China; Gluesweeper: 2100XL, UMAX, China; Electrophoresis: POWERPAC BASIC, BIORAD, USA

\section{Protein digestion, iTRAQ labeling, and peptide fractionation}

Total protein $(100 \mu \mathrm{g})$ was added to a $1.5-\mathrm{mL}$ centrifuge tube. Trypsin enzyme (Hualishi Scientific, Shanghai, China) was added 1:20, vortexed, centrifuged at a low speed 12,000 $\times \mathrm{g}$ for $1 \mathrm{~min}$, and incubated at $37^{\circ} \mathrm{C}$ for $4 \mathrm{~h}$. The peptide solution was frozen-dried after salt removal. The tryptic peptides for each pooled sample were labeled using one of the 8-plex iTRAQ reagents (Applied Biosystems, Foster City, CA, USA) following the manufacturer's protocol. In the 8-plex labeling, reporters 113, 115, and 117 were used for duplicates of the pooled acute ARDS samples, and reporters 114, 116, and 118 were used for duplicates of the pooled recovery ARDS samples. The Shimadzu LC-20AB liquid phase system (Prominence, Shimadzu, Japan) was used, and the separation column was a $5 \mu \mathrm{m} 4.6 \times 250 \mathrm{~mm}$ Gemini C18 column (150 $\mu \mathrm{m}$ inner diameter, $1.8 \mu \mathrm{m}$ column particle size, $35 \mathrm{~cm}$ column length) for liquid phase separation of the sample. The elution peak was monitored at a wavelength of $214 \mathrm{~nm}$, and one component was collected per minute. The samples were combined according to the chromatographic elution peak map to obtain 10 fractions, which were then frozen-dried.

\section{HPLC, LC-MS/MS identification, and quantification of the labeled peptides}

The dried peptide samples were reconstituted with mobile phase A ( $2 \% \mathrm{ACN}, 0.1 \% \mathrm{FA}$ ), centrifuged at $20,000 \times \mathrm{g}$ for $10 \mathrm{~min}$, and the supernatant was taken for injection. Separation was performed using an Easy-nLC 1200 (Thermo Fisher Scientific, San Jose, CA, USA) and tandem self-packed C18 column (75 $\mu \mathrm{m}$ internal diameter, $1.9 \mu \mathrm{m}$ column size, $25 \mathrm{~cm}$ column length) and separated at a flow rate of 200 $\mathrm{nL} / \mathrm{min}$ by the effective gradient. The nanoliter liquid phase separation end was directly connected to a mass spectrometer. The peptides separated by liquid-phase chromatography were ionized by a nanoESI source and then passed to a tandem mass spectrometer Oritrap Exploris 480 (Thermo Fisher Scientific, San Jose, CA, USA) for data-dependent acquisition (DDA) mode detection.

\section{Identification of proteins by quantitative proteomics analysis}

The resulting data were searched in the UniProt database (https://www.uniprot.org/). The data were analyzed using the IQuant (BGI) software[22]. 


\section{Gene ontology enrichment and pathway enrichment analyses}

Gene ontology (GO) (http://www.geneontology.org) is a commonly used bioinformatic tool that provides comprehensive information on the gene function of individual genomic products based on defined features. The Kyoto Encyclopedia of Genes and Genomes (KEGG) (http://www.genome.jp/kegg) is an easy-to-use automated database resource for understanding high-level biological functions and utilities. GO and KEGG pathway analyses of co-upregulated and co-downregulated proteins were performed via The Database for Annotation, Visualization, and Integrated Discovery. The GO analysis consisted of biological processes (BP), cellular components (CC), and molecular functions (MF).

\section{PPI network creation and hub gene identification}

The PPI network of differentially expressed proteins (DEPs) was constructed using the Search Tool for the Retrieval of Interacting Genes (STRING; https://string-db.org/)[23], with a combined score $>0.4$ as the cut-off point. Hub genes were identified using Cytohubba, a plug-in of the Cytoscape software (Cytoscape, 3.9.0)[24]. Significant modules in the PPI network were identified by molecular complex detection (MCODE)[25], another plug-in of Cytoscape software.

\section{Cell culture and stimulation}

A549 cells were purchased from CELLCOOK (http://www.cellcook.com/). A549 cells are human alveolar basal epithelial cells that grow adherently as a monolayer in vitro. The A549 cell line is widely used as a model of lung adenocarcinoma, as well as an in vitro model for type II pulmonary epithelial cells. The cells were cultured in 1640 medium with $10 \%$ fetal bovine serum (FBS). LPS (10 $\mu \mathrm{g} / \mathrm{ml}$, Sigma, St, Louis, MO, USA) was added to the culture medium to stimulate the cells for $48 \mathrm{~h}$.

\section{RNA extraction, reverse transcription, and quantitative real-time PCR}

RNA was extracted using TRIzol reagent (Invitrogen, Carlsbad, CA, USA). cDNA synthesis was performed with $1 \mu \mathrm{g}$ of total RNA and the $5 \times$ HiScript $\triangle \mathrm{qRT}$ SuperMix (Vazyme Biotech, Co., Ltd., Nanjing, China), according to the manufacturer's instructions. Endogenous mRNA levels were measured by real-time PCR analysis based on AceQ qPCR SYBR Green Master Mix (Vazyme Biotech, Co., Ltd., Nanjing, China) detection with a Roche real-time PCR machine. In order to confirm the expression of RNAs, qPCR was performed under the following sequential conditions: 1) $95^{\circ} \mathrm{C}$ for $\left.5 \mathrm{~min}, 2\right) 40$ cycles at $95^{\circ} \mathrm{C}$ for $10 \mathrm{~s}$ and $60^{\circ} \mathrm{C}$ for $34 \mathrm{~s}$. The primers are shown in Table 2. Samples were assayed in duplicate. The $2^{-\triangle \Delta C T}$ methodology was to obtain the ratios after normalizing to endogenous $\beta$-actin.

\section{Western blotting and antibodies}

Protein extracts were analyzed by western blotting according to standard protocols. Cells were harvested and boiled in a $4 \times$ loading buffer. Equal amounts of proteins were resolved by SDS-polyacrylamide gel electrophoresis and transferred onto a nitrocellulose membrane, blocked with $8 \%$ skimmed milk. The membranes were incubated with primary antibodies against RPSA (1:1000 dilution, eBioscience, San 
Diego, CA, USA), and anti-GAPDH (\#5174S, 1:1000 dilution, Cell Signaling Technology, Inc., Danvers, MA, USA) followed by a secondary antibody (\#PMS302, 1:1000 dilution, Proteinbiotechnology, Shanghai, China) bearing an oligonucleotide. After two washes, each membrane was read using a chemiluminescence developing solution (\#180-506, Tanon ${ }^{\text {TM }}$ Femto-sig ECL).

\section{Enzyme-linked immunosorbent assay (ELISA) detection process}

RPSA was detected in A549 cell supernatant using ELISA, according to the manufacturer's instructions. 1) Adding standards and samples in duplicate to the microtiter plate. 2) Adding $50 \mu$ l of standard or sample to the appropriate wells. 3) Adding $100 \mu \mathrm{l}$ of enzyme conjugate to standard wells and sample wells except the blank well, covered with an adhesive strip and incubate for 60 minutes at $37^{\circ} \mathrm{C}$. 4) Washing the microtiter plate 4 times, remove incubation mixture by aspirating contents of the plate into a sink or proper waste container. Using a squirt bottle, fill each well completely with wash solution (1X), then aspirate contents of the plate into a sink or proper waste container. Repeat this procedure for a total of four times. After final wash, invert plate, and blot dry by hitting plate onto absorbent paper or paper towels until no moisture appears. 5) Aspirating all wells, then wash plates four times using wash buffer $(1 \mathrm{X})$. Always adjust your washer to aspirate as much liquid as possible and set fill volume at 350 $\mathrm{ul} /$ well/wash. After final wash, invert plate, and blot dry by hitting plate onto absorbent paper or paper

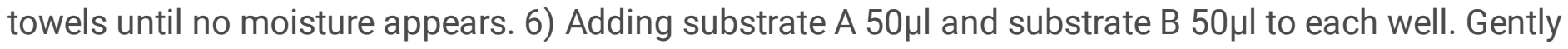
mix and incubate for 15 minutes at $37^{\circ} \mathrm{C}$. 7) Adding $50 \mu$ stop solution to each well. The color in the wells should change from blue to yellow. 8) Reading the Optical Density (O.D.) at $450 \mathrm{~nm}$ using a microtiter plate reader within 15 minutes.

\section{Statistical analysis}

The identification and verification results were based upon statistical evaluation and were expressed as means \pm SDs. Single sample t-tests were used to compare the two groups. P-values $<0.05$ were considered statistically significant. ${ }^{*} P<0.05,{ }^{*} P<0.01,{ }^{\star \star *} P<0.001$.

\section{Results}

\section{Identification of proteins related to ARDS}

In order to estimate the efficiency of high-abundance protein removal, we performed $12 \%$ SDS-PAGE followed by Coomassie blue staining (Supplementary Figure S1). In order to identify the proteins between the acute inflammation and recovery phases, we extracted the intersection 1459 proteins from the three sets of mass spectrometry data, as shown in the venn diagram (Figure $2 A$ ) and heatmap (Figure 2B). In this iTRAQ quantification project, based on the discovery analysis, 398,924 spectra were generated, and 4036 peptides and 1475 proteins were controlled below 1\% FDR. At least one unique peptide was required to qualify a protein. Among all identified proteins, the molecular weight $(\mathrm{kDa})$ of the $55 \%$ of the identified proteins was approximately $10-50 \mathrm{kDa}$, and that of the $10 \%$ of the proteins was more than $100 \mathrm{kDa}$ (Supplementary Figure S2A). The length of about 50\% peptides was 5-10 amino acids (Supplementary 
Figure S2B). Besides, about $70 \%$ of the proteins included no more than two unique peptides. The proteins were identified with low sequence coverage, about $97 \%$ of proteins with less than $30 \%$ sequence coverage (Supplementary Figure S2C).

\section{Comparison of the CUDPs}

As shown in Figure 3A and Figure 3B, we took three pairs of samples that were all detected by LC-MS/MS and used the upset diagram to show the number and ratio of proteins. The volcano plots (Figure 3 ) displayed the CUDPs of recovery/acute inflammation, respectively. The red dots indicate significantly upregulated proteins that passed the screening threshold ( $P$-value $<0.05$ and fold-change $>1.2$ or Log2FC $>0.263)$. The blue dots indicate significantly downregulated proteins that passed the screening threshold (P-value $<0.05$ and fold-change $<0.83$ or Log2FC $<-0.263$ ). The abundance of 19 proteins was significantly increased in the recovery phase (decreased in the acute phase), while the abundance of 34 proteins was significantly decreased in the recovery phase (increased in the acute phase). The detailed results of the differentially abundant proteins are summarized in Table 3.

\section{GO enrichment analysis of 374 CUDPs}

In order to determine the biological features of the CUDPs, GO analysis was performed. Changes in BP of CUDPs were significantly enriched in neutrophil mediated immunity, neutrophil activation involved in immune response and neutrophil degranulation (Figure 4A). The CC analysis showed that CUDPs were enriched in vesicle lumen and cytoplasmic vesicle lumen (Figure 4B). The MF analysis revealed that the CUDPs were enriched in cell adhesion molecule binding, cadherin binding and structural constituent of ribosome (Figure 4C).

\section{KEGG enrichment analysis of CUDPs}

KEGG enrichment analysis of CUDPs was performed to explore the potential mechanism of these CUDPs. CUDPs were mainly involved in Coronavirus disease-COVID-19, Ribosome, Prion disease, and Endocytosis (Figure 5).

\section{Protein-protein interaction analysis}

Fifty-three proteins were differentially expressed in the iTRAQ LC-MS/MS analysis and PPI network analysis. These proteins represent different functions in cell regulation and association with an inflammatory response. In order to identify the most significant clusters of the DEPs, PPI network of DEPs was constituted by STRING. All DEPs were pasted into the STRING website and then analyzed with the Cytoscape software. The 53 proteins formed 34 nodes with 70 edges were involved in constructing the PPI networks. Five proteins did not enter the PPI networks. The protein selection was based on significance and high frequency between recovery and acute by cytoscape analysis (Figure $6 \mathrm{~A}$ ).

\section{Hub genes recognition}


In order to identify the hub gene among the DEPs, Cytohubba, and MCODE, a plug-in Cytoscape was performed. All the gene codes and edges were calculated (Table 4). The most significant module was identified by MCODE (score = 5.33) (Figure 6B ,Table 5). Finally, the top six genes were identified as hub genes by the intersection of 12 algorithms and MCODE (Table 6). The analysis showed that RPSA was discovered as the most top hub gene among DEPs accordingly.

\section{Hub gene RPSA verification in A549 cells}

We searched the hsa05171 pathway diagram and selected some inflammation-related factors for testing to ensure the successful construction of the cell model. RPSA, IL-6, IL-8, and COX2 mRNAs were detected by qPCR. The mRNA levels of all of them were upregulated in A549 cells (Figure 7A). Western blot also confirmed the above statement for RPSA (Figure7B). The ELISA used to test the cell cultures proved that the inflammatory response induced by LPS also supports the increases of RPSA (Figure 7C).

\section{Discussion}

ARDS is a critical condition that poses a serious threat to human health due to its high mortality rate. Although numerous studies investigated the mechanisms underlying ARDS, effective biomarkers for the diagnosis, prognosis, and therapeutic targeting of ARDS remain scarce, and the mechanisms governing ARDS have not been fully elucidated. Quantitative proteomics has been widely applied to detect differential proteins and pathways in many disease models, including ARDS. In this study, an 8-plex ITRAQ analysis enabled the investigation of large-scale protein alterations. The paired BALF samples from three ARDS patients in the acute and recovery phases were selected to identify the hub genes associated with ARDS, as well as their associated biological pathways by integrated bioinformatics analysis. In total, 1475 proteins were identified, including 98 co-upregulated proteins, and 278 codownregulated proteins were identified. Fifty-three proteins were found to be differentially expressed. Finally, the 374 CUDPs were enriched in cell adhesion molecule binding, cytoplasmic vesicle lumen, and neutrophils.

Activated neutrophils are involved in many pathologies, especially infectious and lung diseases, including the ARDS[26]. The most enriched gene set of CUDPs in the BP of GO were neutrophil activation involved in immune response and neutrophil degranulation. According to Robb et al.[27], COVID-19 causes a spectrum of respiratory conditions differing in severity, including mild upper respiratory tract complications, ARDS, and pneumonia (due to secondary infection) in more deleterious cases. Chiumello et al.[28] showed that COVID-19-ARDS is a subset of ARDS. The primary enriched pathways were the Coronavirus disease COVID-19 interaction (hsa05171) and Ribosome (hsa03010). Some of 53 DEPs have been discovered to be related to pulmonary inflammation. For instance, HSP90AB1 was increased in the acute phase in this study, agreeing with a previous study by Ding Ma et al, and he identified that HSP90AB1 obviously up-regulated in ACE2-positive bronchial epithelial cells of patients with mild disease[29]. The COX-2/PGE2 pathway is a classic pro-inflammatory pathway. COX-2 is a pivotal enzyme in the production of prostaglandins, and evidence suggests that COX-2 plays an important role in the 
pathogenesis of ARDS[30]. Kovalchuk et al.[31] showed that COX2, TNFa, IL-6, CCL2, and other cytokines and pathways related to inflammation and fibrosis are significantly upregulated in ARDS. The top six genes were identified as hub genes based on the degree of connectivity in the PPI network and through Cytohubba and MCODE analysis. The results revealed that RPSA is the most core gene, which was ranked first many times by the algorithms.

Alveolar epithelial-type cells are the main target cells being damaged and releasing the inflammatory mediators during ARDS [14]. LPS-induced A549 cells are a common model used to research pulmonary inflammation and injury. In this study, we evaluated the role of the RPSA protein in the regulation of inflammation in A549 cells treated with LPS. In order to verify our hypothesis, we used $10 \mathrm{ug} / \mathrm{ml}$ LPS to induce inflammation in A549 cells. After $48 \mathrm{~h}$ of stimulation, we firstly detect their mRNA expression level. Surprisingly, the RNA expression levels of RPSA showed elevated expression in induced A549 cells compared with the control group. Consistent with previous results, the protein expression of RPSA was upregulated by western blot. Given that RPSA is detected in the BALF, we used ELISA to detect RPSA in the cell culture supernatant of the processed samples compared with the control group. Consistent with the mRNA and protein expression, ELISA also showed that RPSA was highly expressed in the supernatant of A549 induced by LPS.

This study had limitations. The pairs of samples consisted of one sample in the acute phase and one sample in the recovery phase. Still, no sample without ARDS was included, and there is a possibility that some proteins were still affected in the recovery phase. This study only identified proteins and supposed mechanisms based on bioinformatics, but these mechanisms were not validated in vitro. A future study should specifically examine the value of BALF RPSA for the screening for ARDS.

In conclusion, based on ITRAQ proteomic profiling, a dataset to summarize protein alterations in the BALF of patients with ARDS was generated. The results might suggest novel biomarker candidates and potential therapeutic targets for ARDS. RPSA might be a potential biomarker or therapeutic target in ARDS.

\section{Declarations}

\section{ACKNOWLEDGEMENTS}

Not applicable.

\section{AUTHOR CONTRIBUTIONS}

L.Z., G.S., H.Z., and H.G. conceived and designed the project. Y.X., L.G. and L.Guo. collected the clinical samples, performed most of the experiments and analyzed the data. H.L., M.S., Q.Y., N.L., M.F., H.X. and J.L. provided technical assistance. Y.X. and L.Z. wrote the manuscript.

\section{FUNDING}


This study was funded by the Project for enhancing clinical and basic medical collaboration of Anhui Medical University (2020xkjT015) and Scientific Research Fund project of Anhui Medical University (Clinical Science Foundation) (2021xkj151)

\section{AVAILABILITY OF DATA AND MATERIALS}

All of the datasets in this study can be obtained by reasonable request to the corresponding authors.

\section{ETHICS APPROVAL}

Three cases of ARDS patients were selected in the First Affiliated Hospital of Anhui Medical University from October 2020 to November 2020. This study was approved by the Ethics Committee of the First Affiliated Hospital of Anhui Medical University. Informed consent was obtained from patients or their closest relatives in accordance with the 2013 (7th Edition) Declaration of Helsinki.

\section{CONSENT FOR PUBLICATION}

Not applicable.

\section{COMPETING INTERESTS}

The authors declare no competing financial interests.

\section{References}

1. Thompson, B.T., R.C. Chambers, and K.D. Liu, Acute Respiratory Distress Syndrome. N Engl J Med, 2017. 377(6): p. 562-572.

2. Bellani, G., et al., Epidemiology, Patterns of Care, and Mortality for Patients With Acute Respiratory Distress Syndrome in Intensive Care Units in 50 Countries. JAMA, 2016. 315(8): p. 788-800.

3. Chiu, L.C., et al., Dynamic driving pressure associated mortality in acute respiratory distress syndrome with extracorporeal membrane oxygenation. Ann Intensive Care, 2017. 7(1): p. 12.

4. Fan, E., D. Brodie, and A.S. Slutsky, Acute Respiratory Distress Syndrome: Advances in Diagnosis and Treatment. JAMA, 2018. 319(7): p. 698-710.

5. Liu, L., et al., Practice of diagnosis and management of acute respiratory distress syndrome in mainland China: a cross-sectional study. J Thorac Dis, 2018. 10(9): p. 5394-5404.

6. Cifani, P. and A. Kentsis, Towards comprehensive and quantitative proteomics for diagnosis and therapy of human disease. Proteomics, 2017. 17(1-2).

7. Smith, J.G. and R.E. Gerszten, Emerging Affinity-Based Proteomic Technologies for Large-Scale Plasma Profiling in Cardiovascular Disease. Circulation, 2017. 135(17): p. 1651-1664.

8. Wiese, S., et al., Protein labeling by iTRAQ: a new tool for quantitative mass spectrometry in proteome research. Proteomics, 2007. 7(3): p. 340-50. 
9. Liu, X., et al., Differential Proteomic Analysis of Dimethylnitrosamine (DMN)-Induced Liver Fibrosis. Proteomics, 2017. 17(22).

10. Zhang, L. and J.E. Elias, Relative Protein Quantification Using Tandem Mass Tag Mass Spectrometry. Methods Mol Biol, 2017. 1550: p. 185-198.

11. Nunez, E.V., G.B. Domont, and F.C.S. Nogueira, iTRAQ-Based Shotgun Proteomics Approach for Relative Protein Quantification. Methods Mol Biol, 2017. 1546: p. 267-274.

12. Beitler, J.R., et al., Personalized medicine for ARDS: the 2035 research agenda. Intensive Care Med, 2016. 42(5): p. 756-767.

13. Matthay, M.A., et al., Acute respiratory distress syndrome. Nat Rev Dis Primers, 2019. 5(1): p. 18.

14. Han, S. and R.K. Mallampalli, The acute respiratory distress syndrome: from mechanism to translation. J Immunol, 2015. 194(3): p. 855-60.

15. Brassart, B., et al., Tumour cell blebbing and extracellular vesicle shedding: key role of matrikines and ribosomal protein SA. Br J Cancer, 2019. 120(4): p. 453-465.

16. Givant-Horwitz, V., B. Davidson, and R. Reich, Laminin-induced signaling in tumor cells: the role of the M(r) 67,000 laminin receptor. Cancer Res, 2004. 64(10): p. 3572-9.

17. Vania, L., et al., Patented therapeutic approaches targeting $L R P / L R$ for cancer treatment. Expert Opin Ther Pat, 2019. 29(12): p. 987-1009.

18. Pesapane, A., et al., Recent Advances in the Function of the $67 \mathrm{kDa}$ Laminin Receptor and its Targeting for Personalized Therapy in Cancer. Curr Pharm Des, 2017. 23(32): p. 4745-4757.

19. Kane, B.A., et al., Differential expression and regulation of the non-integrin 37/67-kDa laminin receptor on peripheral blood leukocytes of healthy individuals and patients with rheumatoid arthritis. Sci Rep, 2019. 9(1): p. 1149.

20. Sun, Q., et al., Ribosomal Protein SA-Positive Neutrophil Elicits Stronger Phagocytosis and Neutrophil Extracellular Trap Formation and Subdues Pro-Inflammatory Cytokine Secretion Against Streptococcus suis Serotype 2 Infection. Front Immunol, 2020. 11: p. 585399.

21. Knaus, W.A., et al., APACHE II: a severity of disease classification system. Crit Care Med, 1985. 13(10): p. 818-29.

22. Wen, B., et al., IQuant: An automated pipeline for quantitative proteomics based upon isobaric tags. Proteomics, 2014. 14(20): p. 2280-2285.

23. Franceschini, A., et al., STRING v9.1: protein-protein interaction networks, with increased coverage and integration. Nucleic Acids Res, 2013. 41(Database issue): p. D808-15.

24. Chin, C.H., et al., cytoHubba: identifying hub objects and sub-networks from complex interactome. BMC Syst Biol, 2014. 8 Suppl 4: p. S11.

25. Bandettini, W.P., et al., MultiContrast Delayed Enhancement (MCODE) improves detection of subendocardial myocardial infarction by late gadolinium enhancement cardiovascular magnetic resonance: a clinical validation study. J Cardiovasc Magn Reson, 2012. 14: p. 83. 
26. Ekpenyong, A.E., et al., Mechanical deformation induces depolarization of neutrophils. Sci Adv, 2017. 3(6): p. e1602536.

27. Robb, C.T., et al., Non-steroidal anti-inflammatory drugs, prostaglandins, and COVID-19. Br J Pharmacol, 2020. 177(21): p. 4899-4920.

28. Chiumello, D., et al., Physiological and quantitative CT-scan characterization of COVID-19 and typical ARDS: a matched cohort study. Intensive Care Med, 2020. 46(12): p. 2187-2196.

29. Ma, D., et al., Single-cell RNA sequencing identify SDCBP in ACE2-positive bronchial epithelial cells negatively correlates with COVID-19 severity. J Cell Mol Med, 2021. 25(14): p. 7001-7012.

30. Sun, J., et al., Dexmedetomidine inhibits apoptosis and expression of COX-2 induced by lipopolysaccharide in primary human alveolar epithelial type 2cells. Biochem Biophys Res Commun, 2019. 517(1): p. 89-95.

31. Kovalchuk, A., et al., Fighting the storm: could novel anti-TNFalpha and anti-lL-6 C. sativa cultivars tame cytokine storm in COVID-19? Aging (Albany NY), 2021. 13(2): p. 1571-1590.

\section{Tables}

Table 1. Demographic characteristics of ARDS patients for iTRAQ analysis.

\begin{tabular}{|llllllll|}
\hline Case & Sex & Age & Etiology & $\begin{array}{l}\text { Minimum } \\
\text { P/F } \\
(\mathrm{mmHg})\end{array}$ & $\begin{array}{l}\text { APACHEII } \\
\text { score }\end{array}$ & $\begin{array}{l}\text { SOFA } \\
\text { score }\end{array}$ & Prognosis \\
\hline 1 & Female & 27 & Severe pneumonia & 68 & 20 & 10 & Recovered \\
\hline 2 & Male & 62 & $\begin{array}{l}\text { Severe } \\
\text { pneumonia(inhalation) }\end{array}$ & 55.7 & 18 & 10 & Improved \\
\hline 3 & Female & 73 & Severe sepsis & 91 & 14 & 8 & Improved \\
\hline
\end{tabular}

Table 2. Primer sequences and lengths of amplified templates for real-time quantitative polymerase chain reaction (qPCR). 


\begin{tabular}{|ll|}
\hline Target Gene & Sequence \\
\hline IL-6 & 5'-GTGTTGCCTGCTGCCTTC-3' \\
& 5'-AGTGCCTCTTTGCTGCTTTC-3' \\
\hline IL-8 & 5'-GACATACTCCAAACCTTTCCAC-3' \\
& 5'- CTTCTCCACAACCCTCTGC-3' \\
\hline COX-2 & 5'- CCCTTCTGCCTGACACCTTT-3' \\
& 5'- 'TTCTGTACTGCGGGTGGAAC-3' \\
& 5'-GTGGCCGAGGACTTTGATTG-3' \\
& 5'-CCTGTAACAACGCATCTCATATT-3' \\
RPSA & 5'-TTTGTGGAACAGTGAGGGCT-3' \\
& 5'-GCTGCCTGGATCTGGTTAGT-3' \\
\hline
\end{tabular}

Table 3. The 53 differentially expressed proteins (DEPs) between the RG and AIG 


Uniprot ID Log2FC Pvalue $\begin{aligned} & \text { Gene } \\ & \text { symbol }\end{aligned}$

\begin{tabular}{|c|c|c|c|c|}
\hline HBB_HUMAN & 2.627773944 & 0.017116429 & HBB & Hemoglobin subunit beta \\
\hline HBA_HUMAN & 2.65529676 & 0.015447252 & HBA1 & Hemoglobin subunit alpha \\
\hline HBD_HUMAN & 2.210485866 & 0.018627454 & HBD & Hemoglobin subunit delta \\
\hline CAH1_HUMAN & 2.521450132 & 0.025770378 & CA1 & Carbonic anhydrase 1 \\
\hline LEG1H_HUMAN & 1.147659333 & 0.021488374 & LEG1 & Protein LEG1 homolog \\
\hline SPTB1_HUMAN & 2.087092251 & 0.046460874 & SPTB & Spectrin beta chain \\
\hline RBMX_HUMAN & 0.881975836 & 0.020501773 & RBMX & $\begin{array}{l}\text { RNA-binding motif protein, } \mathrm{X} \\
\text { chromosome }\end{array}$ \\
\hline GALT_HUMAN & 0.393981481 & 0.020570424 & GALT & $\begin{array}{l}\text { Galactose-1-phosphate } \\
\text { uridylyltransferase }\end{array}$ \\
\hline PRDX2_HUMAN & 2.457006621 & 0.048327571 & PRDX2 & Peroxiredoxin-2 \\
\hline HBG1_HUMAN & 2.46538042 & 0.032869509 & HBG1 & Hemoglobin subunit gamma-1 \\
\hline PSB1_HUMAN & 0.379463091 & 0.006043111 & PSMB1 & Proteasome subunit beta type- 1 \\
\hline KLK10_HUMAN & 0.749255172 & 0.033499861 & KLK10 & Kallikrein-10 \\
\hline HV313_HUMAN & 0.58344586 & 0.007459594 & IGHV3-13 & $\begin{array}{l}\text { Immunoglobulin heavy variable } \\
\text { 3-13 }\end{array}$ \\
\hline
\end{tabular}

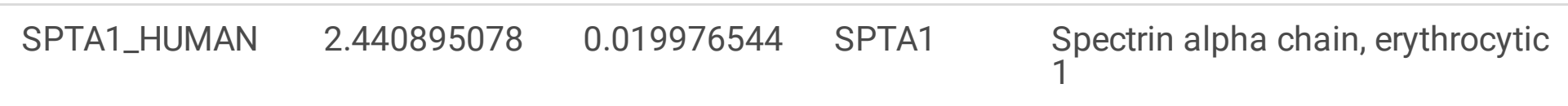

$\begin{array}{lllll}\text { PMGE_HUMAN } & 0.812211578 & 0.044945408 & \text { BPGM } & \text { Bisphosphoglycerate m } \\ \text { PCKGM_HUMAN } & 0.299326639 & 0.049074472 & \text { PCK2 } & \begin{array}{l}\text { Phosphoenolpyruvate } \\ \text { carboxykinase [GTP], } \\ \text { mitochondrial }\end{array}\end{array}$

\begin{tabular}{lllll} 
HS90B_HUMAN & -0.480596476 & 0.007619525 & HSP90AB1 & Heat shock protein HSP 90-beta \\
RSSA_HUMAN & -0.472690289 & 0.025227593 & RPSA & 40S ribosomal protein SA \\
\hline EIF3E_HUMAN & -0.390708644 & 0.032985467 & EIF3E & $\begin{array}{l}\text { Eukaryotic translation initiation } \\
\text { factor 3 subunit E }\end{array}$
\end{tabular}

\begin{tabular}{lllll} 
K2C4_HUMAN & -0.492516261 & 0.045628768 & KRT4 & Keratin, type II cytoskeletal 4 \\
\hline PSB5_HUMAN & -0.565192039 & 0.046053559 & PSMB5 & Proteasome subunit beta type-5 \\
IPO4_HUMAN & -0.413558863 & 0.039795041 & IPO4 & Importin-4
\end{tabular}

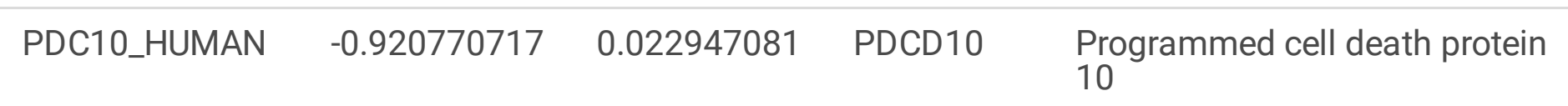

USO1_HUMAN $\quad-0.946038187 \quad 0.02370787 \quad$ USO1 $\quad$ General vesicular transport 
factor $p 115$

\begin{tabular}{|c|c|c|c|c|}
\hline SC31A_HUMAN & -0.411900273 & 0.043970593 & SEC31A & Protein transport protein Sec31A \\
\hline LA_HUMAN & -0.313811738 & 0.008750025 & SSB & Lupus La protein \\
\hline FUMH_HUMAN & -0.536132104 & 0.048848794 & $\mathrm{FH}$ & $\begin{array}{l}\text { Fumarate hydratase, } \\
\text { mitochondrial }\end{array}$ \\
\hline SNRPA_HUMAN & -1.494449366 & 0.03138552 & SNRPA & $\begin{array}{l}\text { U1 small nuclear } \\
\text { ribonucleoprotein A }\end{array}$ \\
\hline LMNB1_HUMAN & -2.497840747 & 0.034597297 & LMNB1 & Lamin-B1 OS=Homo sapiens \\
\hline AL3B1_HUMAN & -0.600144637 & 0.04066091 & ALDH3B1 & $\begin{array}{l}\text { Aldehyde dehydrogenase family } \\
3 \text { member B1 }\end{array}$ \\
\hline RS5_HUMAN & -0.510399958 & 0.016076005 & RPS5 & $40 \mathrm{~S}$ ribosomal protein S5 \\
\hline PSMD8_HUMAN & -0.391098914 & 0.030352322 & PSMD8 & $\begin{array}{l}\text { 26S proteasome non-ATPase } \\
\text { regulatory subunit } 8\end{array}$ \\
\hline NASP_HUMAN & -0.505129065 & 0.031247282 & NASP & $\begin{array}{l}\text { Nuclear autoantigenic sperm } \\
\text { protein }\end{array}$ \\
\hline RS25_HUMAN & -1.031973977 & 0.048764712 & RPS25 & 40 S ribosomal protein S25 \\
\hline PFKAP_HUMAN & -0.474427166 & 0.036422564 & PFKP & $\begin{array}{l}\text { ATP-dependent 6- } \\
\text { phosphofructokinase, platelet } \\
\text { type }\end{array}$ \\
\hline PSMD6_HUMAN & -0.918268455 & 0.042373214 & PSMD6 & $\begin{array}{l}26 \mathrm{~S} \text { proteasome non-ATPase } \\
\text { regulatory subunit } 6\end{array}$ \\
\hline DEN11_HUMAN & -3.06247017 & 0.007101412 & DENND11 & $\begin{array}{l}\text { DENN domain-containing protein } \\
11\end{array}$ \\
\hline S35U4_HUMAN & -2.374981406 & 0.013025699 & SLC35A4 & $\begin{array}{l}\text { SLC35A4 upstream open reading } \\
\text { frame protein }\end{array}$ \\
\hline HNRPQ_HUMAN & -0.538422185 & 0.002871159 & SYNCRIP & $\begin{array}{l}\text { Heterogeneous nuclear } \\
\text { ribonucleoprotein Q }\end{array}$ \\
\hline DJC13_HUMAN & -0.326652616 & 0.018838668 & DNAJC13 & $\begin{array}{l}\text { DnaJ homolog subfamily C } \\
\text { member } 13\end{array}$ \\
\hline COX2_HUMAN & -2.584175982 & 0.024334787 & MT-CO2 & Cytochrome c oxidase subunit 2 \\
\hline FABP4_HUMAN & -0.891392428 & 0.029084499 & FABP4 & $\begin{array}{l}\text { Fatty acid-binding protein, } \\
\text { adipocyte }\end{array}$ \\
\hline EF1D_HUMAN & -0.708277213 & 0.007120905 & EEF1D & Elongation factor 1-delta \\
\hline FCERG_HUMAN & -1.306211684 & 0.023721845 & FCER1G & $\begin{array}{l}\text { High affınity immunoglobulin } \\
\text { epsilon receptor subunit gamma }\end{array}$ \\
\hline SKP1_HUMAN & -0.673831792 & 0.040215231 & SKP1 & $\begin{array}{l}\text { S-phase kinase-associated } \\
\text { protein } 1\end{array}$ \\
\hline
\end{tabular}




\begin{tabular}{lllll} 
CTBP1_HUMAN & -1.239318276 & 0.022408252 & CTBP1 & C-terminal-binding protein 1 \\
\hline DC1I2_HUMAN & -0.438790689 & 0.010799153 & DYNC1I2 & $\begin{array}{l}\text { Cytoplasmic dynein 1 } \\
\text { intermediate chain 2 }\end{array}$ \\
\hline GLPK3_HUMAN & -0.873261218 & 0.001988595 & GK3P & Glycerol kinase 3 \\
\hline PDIA6_HUMAN & -0.294379172 & 0.021287533 & PDIA6 & Protein disulfide-isomerase A6 \\
\hline H2A3_HUMAN & -1.019243294 & 0.030188071 & H2AW & Histone H2A type 3 \\
\hline WBP2_HUMAN & -0.673205102 & 0.004978431 & WBP2 & WW domain-binding protein 2 \\
\hline CNTP4_HUMAN & -2.890928445 & 0.021512285 & CNTNAP4 & $\begin{array}{l}\text { Contactin-associated protein-like } \\
4\end{array}$
\end{tabular}

Table 4. The top-10 proteins of each algorithm (12) and gene frequency by Cytohubba.

\begin{tabular}{|llllll|}
\hline MCC & DMNC & MNC & Degree & EPC & BottleNeck \\
\hline RPSA & SKP1 & RPSA & RPSA & RPSA & RPSA \\
\hline RPS5 & PSMB5 & RPS5 & HBA1 & RPS5 & HBA1 \\
\hline RPS25 & EEF1D & RPS25 & RPS5 & RPS25 & HSP90AB1 \\
\hline PSMD8 & RPS5 & PSMD8 & PSMD8 & EIF3E & SYNCRIP \\
\hline EIF3E & RPS25 & EIF3E & RPS25 & PSMD8 & SPTB \\
\hline PSMB1 & SPTB & SYNCRIP & EIF3E & SYNCRIP & DYNC112 \\
\hline PSMD6 & HBG1 & PSMB1 & SYNCRIP & HBA1 & FH \\
\hline SKP1 & US01 & PSMD6 & HSP90AB1 & PSMB1 & SKP1 \\
\hline PSMB5 & SPTA1 & HBA1 & PSMB1 & EEF1D & RPS25 \\
\hline EEF1D & DYNC112 & SKP1 & PSMD6 & HSP90AB1 & PSMB1 \\
\hline
\end{tabular}




\begin{tabular}{|llllll|}
\hline EcCentricity & Closeness & Radiality & Betweenness & Stress & $\begin{array}{l}\text { Clustering } \\
\text { Coefficient }\end{array}$ \\
\hline HBA1 & RPSA & RPSA & RPSA & RPSA & EEF1D \\
\hline HSP90AB1 & HBA1 & HBA1 & HBA1 & HBA1 & CA1 \\
\hline RPSA & RPS5 & HSP90AB1 & HSP90AB1 & HSP90AB1 & PSMB5 \\
\hline SYNCRIP & HSP90AB1 & RPS5 & DYNC112 & DYNC112 & PDIA6 \\
\hline SPTB & RPS25 & RPS25 & SPTB & SPTB & PRDX2 \\
\hline DYNC112 & PSMD8 & SYNCRIP & US01 & PSMD8 & PSMB1 \\
\hline SKP1 & SYNCRIP & PSMD8 & RPS5 & RPS5 & PSMD6 \\
\hline RPS25 & EIF3E & EIF3E & SKP1 & US01 & RPS25 \\
RPS5 & PSMB1 & PSMB1 & PSMD8 & SYNCRIP & RBMX \\
\hline HBG1 & SPTB & SPTB & SYNCRIP & EIF3E & SSB \\
\hline
\end{tabular}

\begin{tabular}{|ll|}
\hline Protein symbol & Statistical frequency \\
\hline RPSA, RPS5, and RPS25 & 10 \\
\hline HBA1 and SYNCRIP & 9 \\
\hline HSP90AB1 andPSMD8 & 8 \\
\hline EIF3E,PSMB1, and SPTB & 7 \\
\hline
\end{tabular}

Table 5. The major cluster top10 hub genes identified by MCODE.

\begin{tabular}{|lllll|}
\hline Cluster & Score & Nodes & Edges & Node IDs \\
\hline 1 & 5.333 & 10 & 24 & $\begin{array}{l}\text { RPS25, PSMB5, RPS5, SKP1, RPSA, PSMB1, EIF3E, EEF1D, } \\
\text { PSMD6, PSMD8 }\end{array}$ \\
\hline 2 & 3.667 & 7 & 11 & DYNC112, HBG1, HBD, USO1, HBB, SPTB, SPTA1 \\
\hline
\end{tabular}

Table 6. Six intersections selected by Cytohubba and MCODE as hub genes. 


\begin{tabular}{|lllll|}
\hline $\begin{array}{l}\text { Gene } \\
\text { symbol }\end{array}$ & Log2FC & frequency & Description & P value \\
\hline RPSA & -0.468575285 & 10 & 40Sribosomal protein SA & 0.025227593 \\
\hline RPS5 & -0.507471255 & 10 & 40S ribosomal protein S5 & 0.016076005 \\
\hline RPS25 & -0.993420327 & 10 & 40S ribosomal protein S25 & 0.048764712 \\
\hline PSMD8 & -0.387680737 & 8 & $\begin{array}{l}\text { 26S proteasome non-ATPase regulatory } \\
\text { subunit 8 }\end{array}$ & 0.030352322 \\
\hline EIF3E & -0.387088397 & 7 & $\begin{array}{l}\text { Eukaryotic translation initiation factor 3 } \\
\text { subunit E }\end{array}$ & 0.032985467 \\
\hline PSMB1 & 0.380074002 & 7 & Proteasome subunit beta type-1 & 0.006043111 \\
\hline
\end{tabular}

\section{Figures}




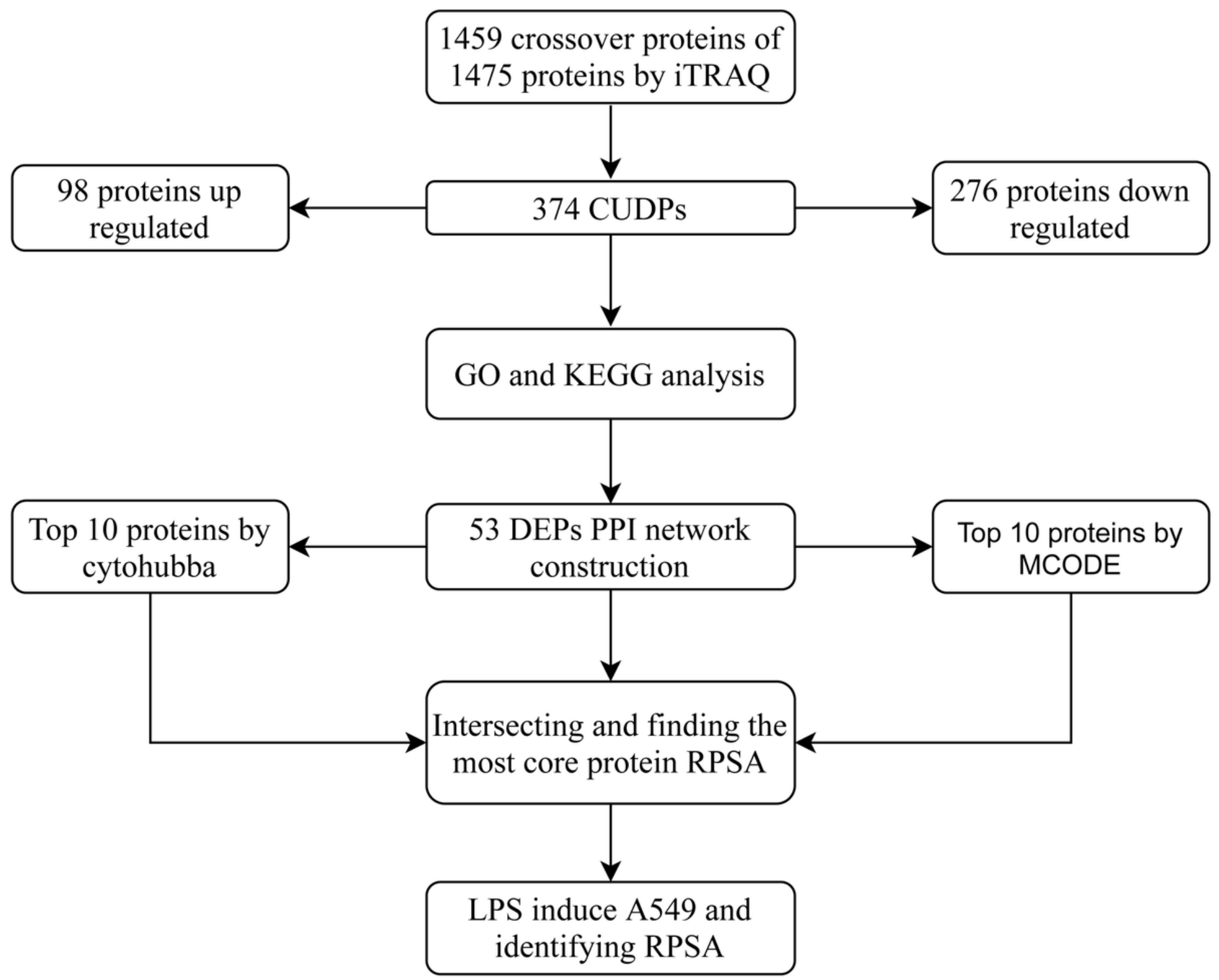

Figure 1

The schematic outline of the experimental workflow for ARDS biomarkers discovery and verification. 


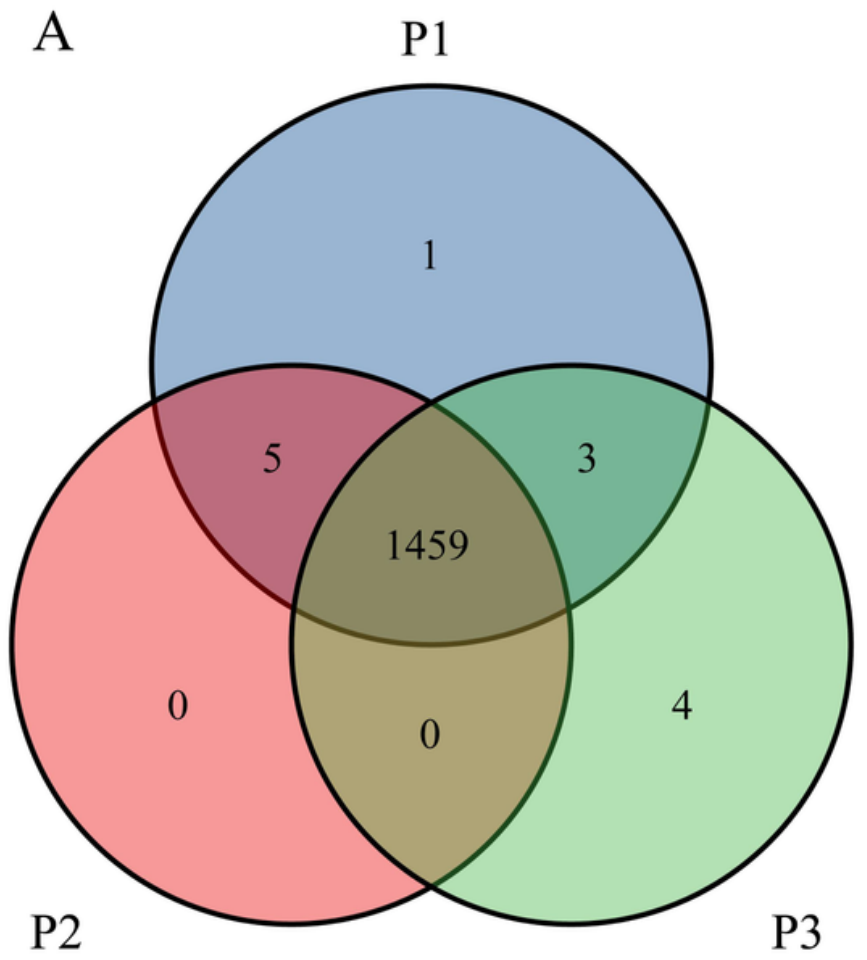

B

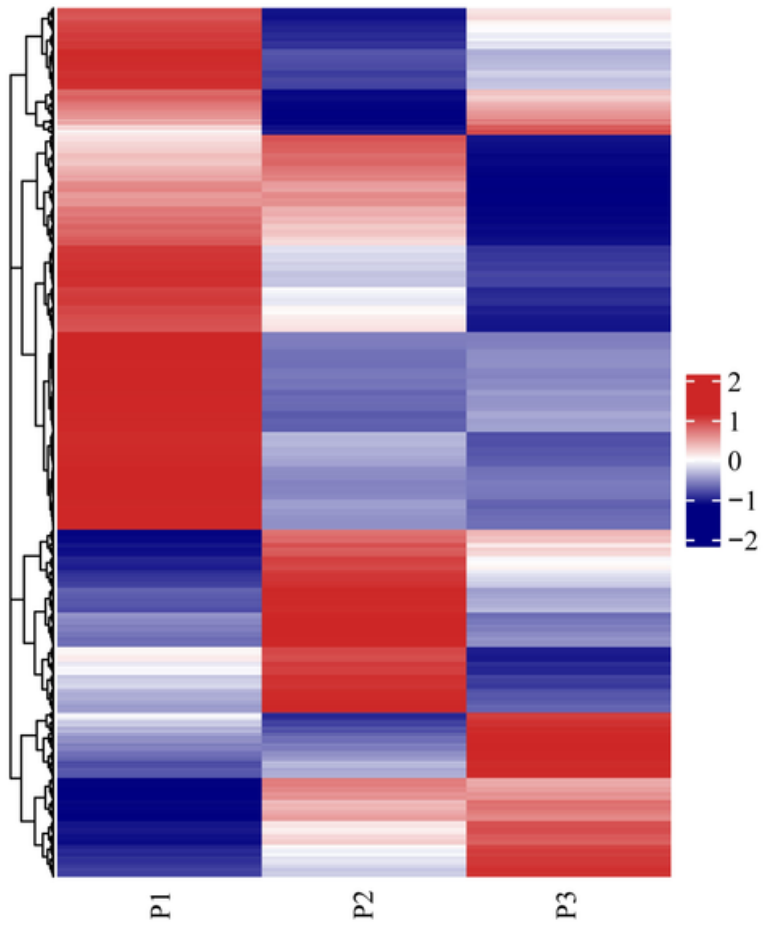

Figure 2

(A) Venn diagram of patient \#1, patient \#2, and patient \#3 showing overlap of 1459 proteins. (B) Heatmap of 1459 proteins screened by R packages "pheatmap" in Rstudio software. Red areas represent highly expressed genes, and blue areas represent lowly expressed genes in three patients with protein expression. P1: Patient 1, P2: Patient 2, P3: Patient 3.

A

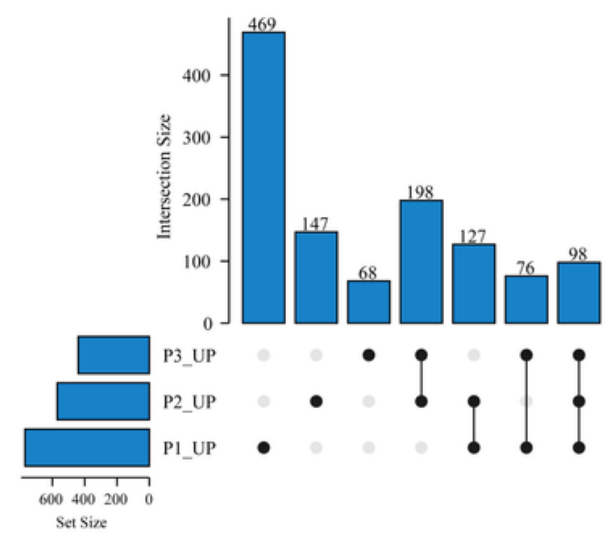

B

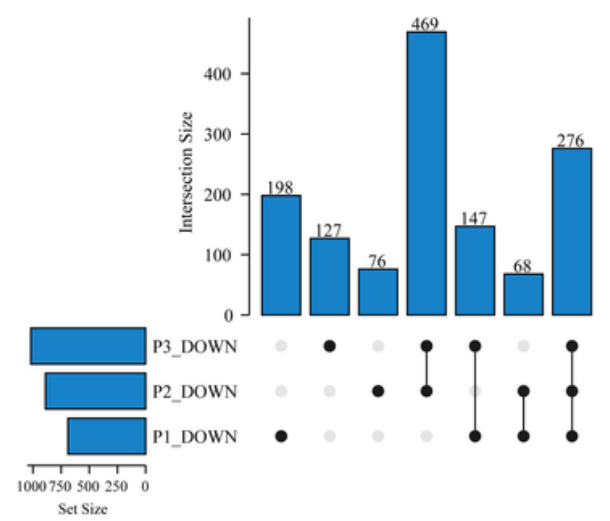

$\mathrm{C}$

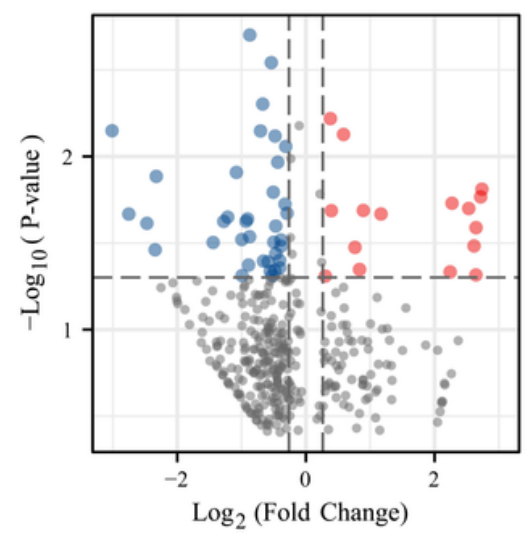

Figure 3

(A/B) Upset graph showing the 98 upregulated and 276 down-regulated proteins. (C) Volcano plot analysis identifying the differentially expressed proteins (DEPS). The red dots represent 19 upregulated 
proteins, and the blue dots represent 34 downregulated proteins.

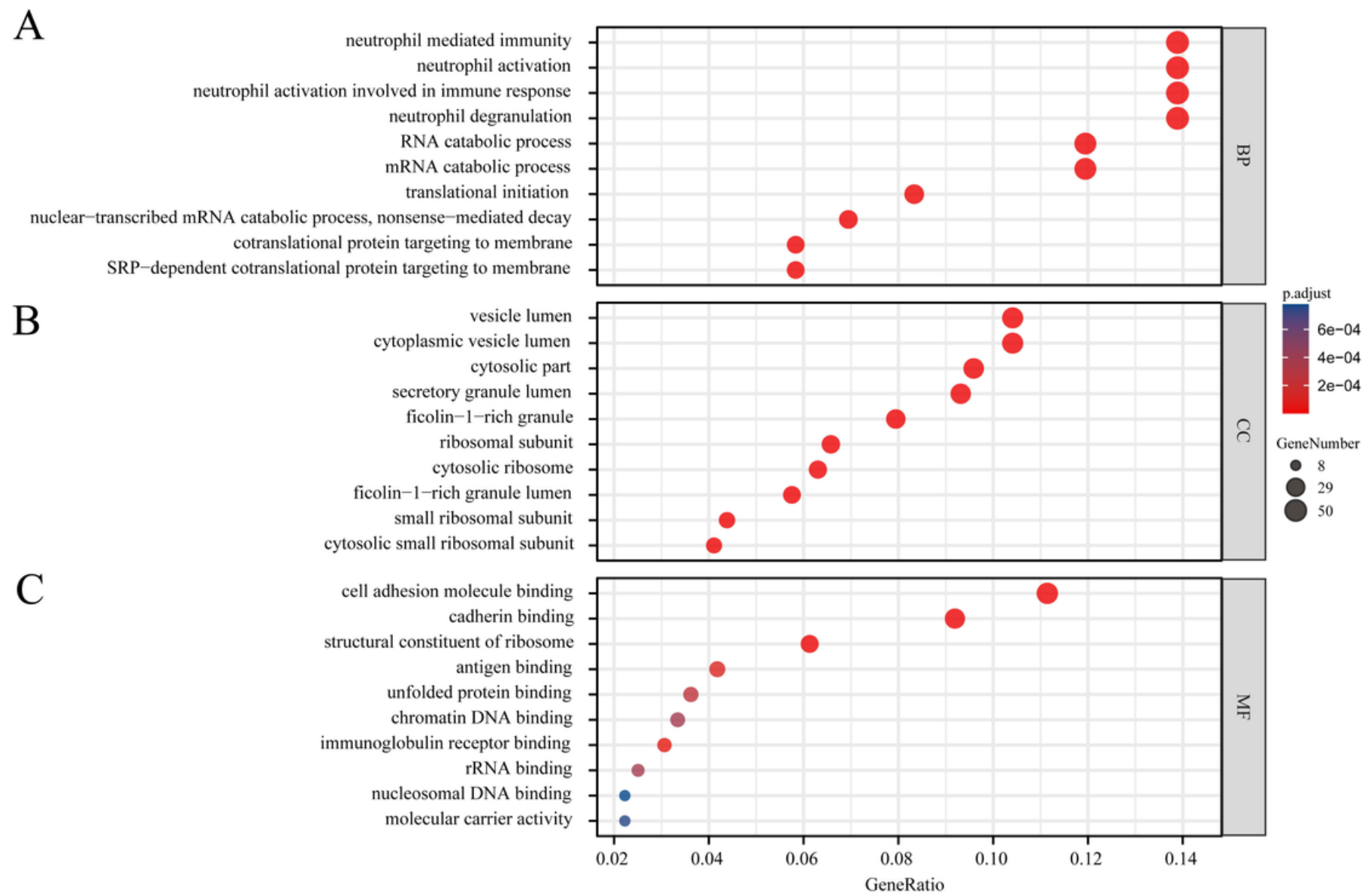

\section{Figure 4}

Gene ontology (GO) enrichment result of CUDPs. (A) Biological processes (BP). (B) Cellular components (CC). (C) Molecular functions (MF). The X-axis label represents the protein ratio, and the Y-axis label represents $\mathrm{GO}$ terms. The size of the circle represents the protein count. Different colors of circles represent different adjusted P-values. 


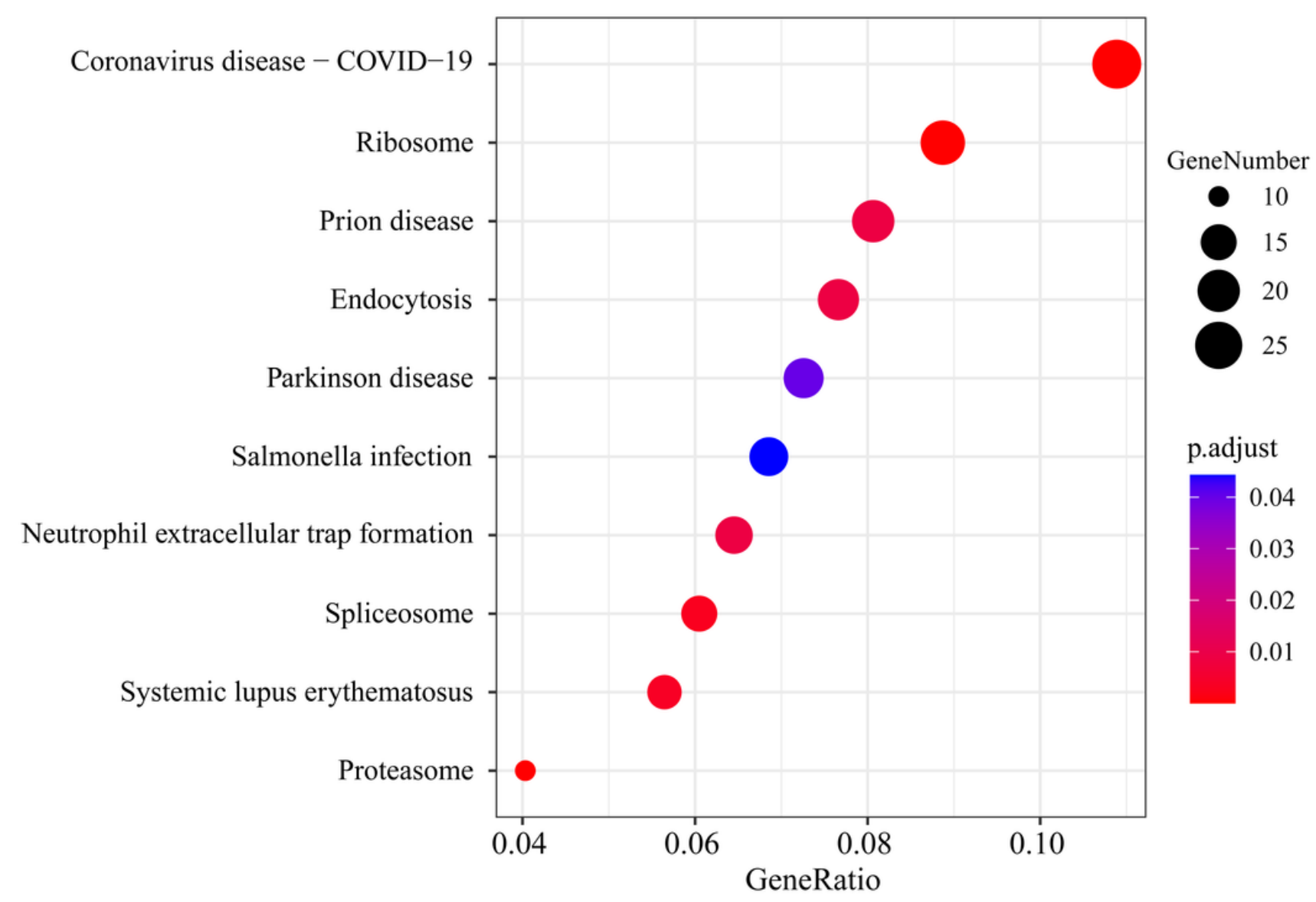

\section{Figure 5}

Kyoto Encyclopedia of Genes and Genomes (KEGG) pathway analysis of differentially expressed proteins. Advanced bubble chart showing the enrichment of CUDPs in signaling pathways. Y-axis labels represent the pathways. X-axis labels represent rich factors. The size and color of the bubble represent the amount of CUDPs enriched in pathway and enrichment significance, respectively. 

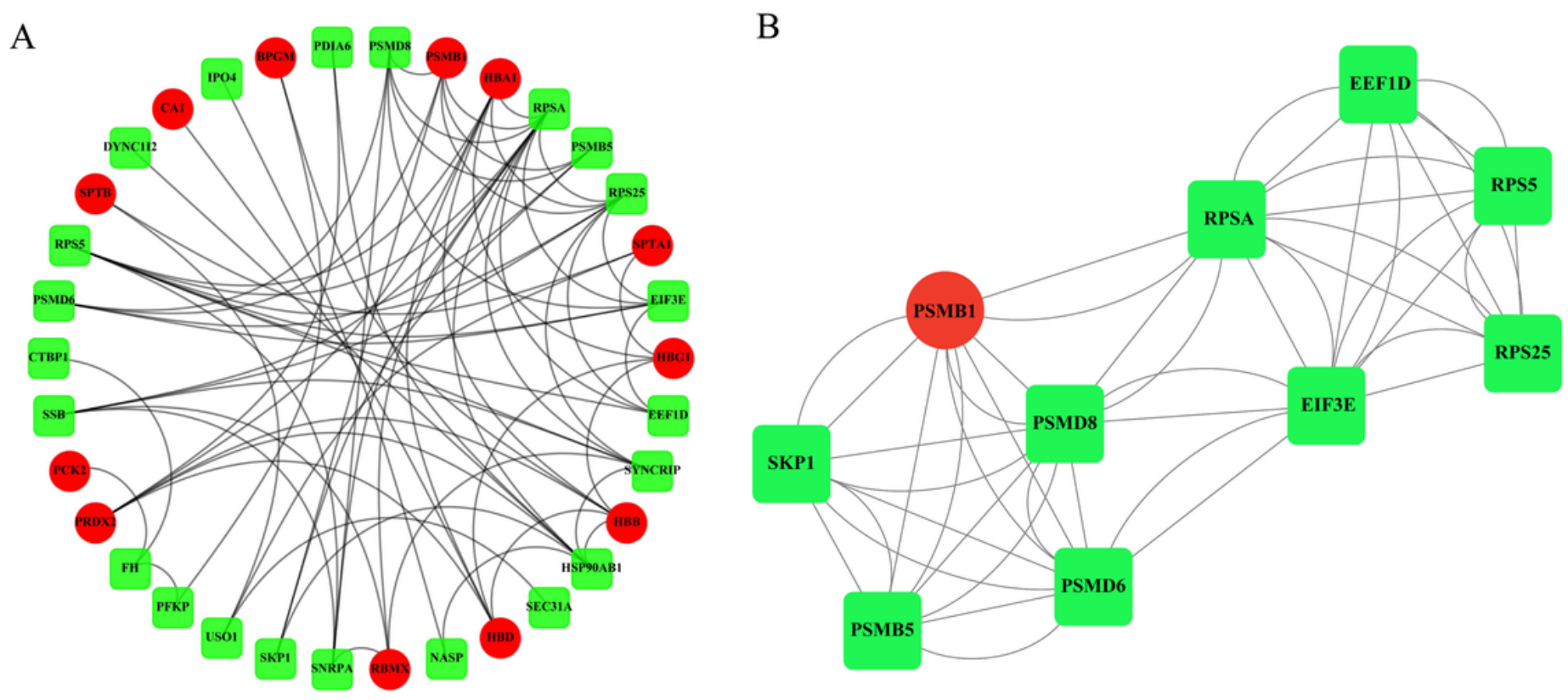

Figure 6

The PPI network and the most significant modules of differentially expressed proteins (DEPs). (A) The PPI network was analyzed by the String software. There were 34 nodes, and 70 edged in the PPI network. (B) The most significant module was identified by MCODE (score $=5.33$ ). The red circle represents the upregulated proteins, and the green boxes represent the downregulated proteins. 
A

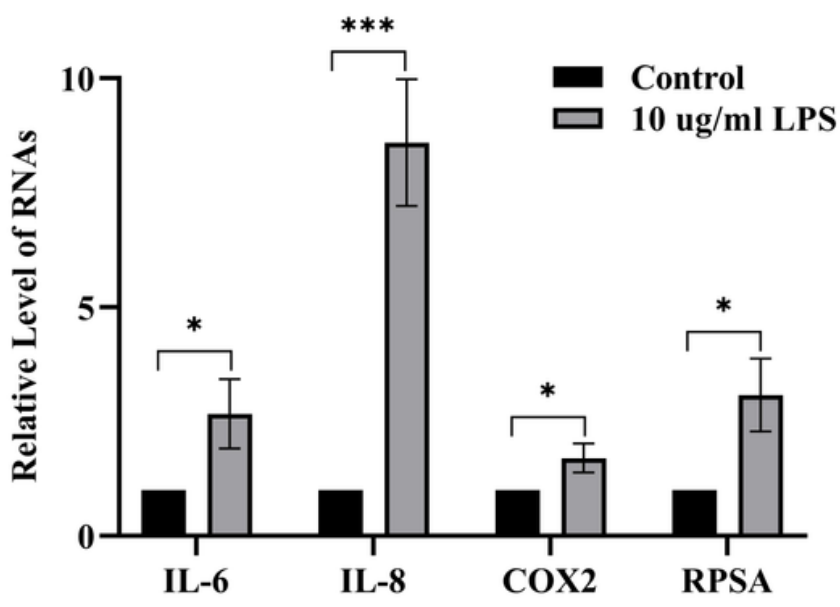

$\mathrm{B}$

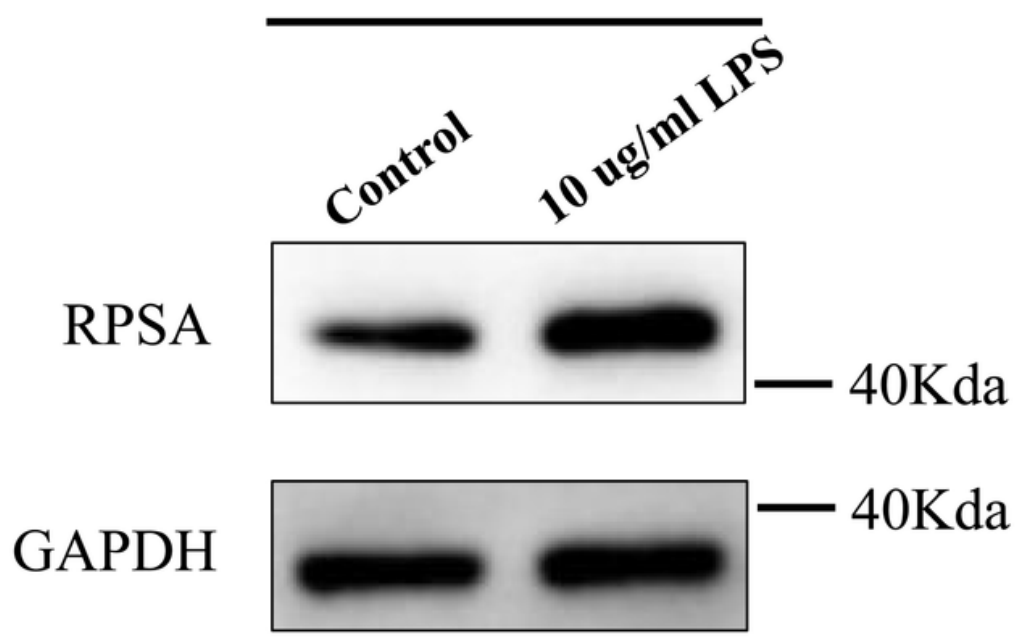

$\mathrm{C}$
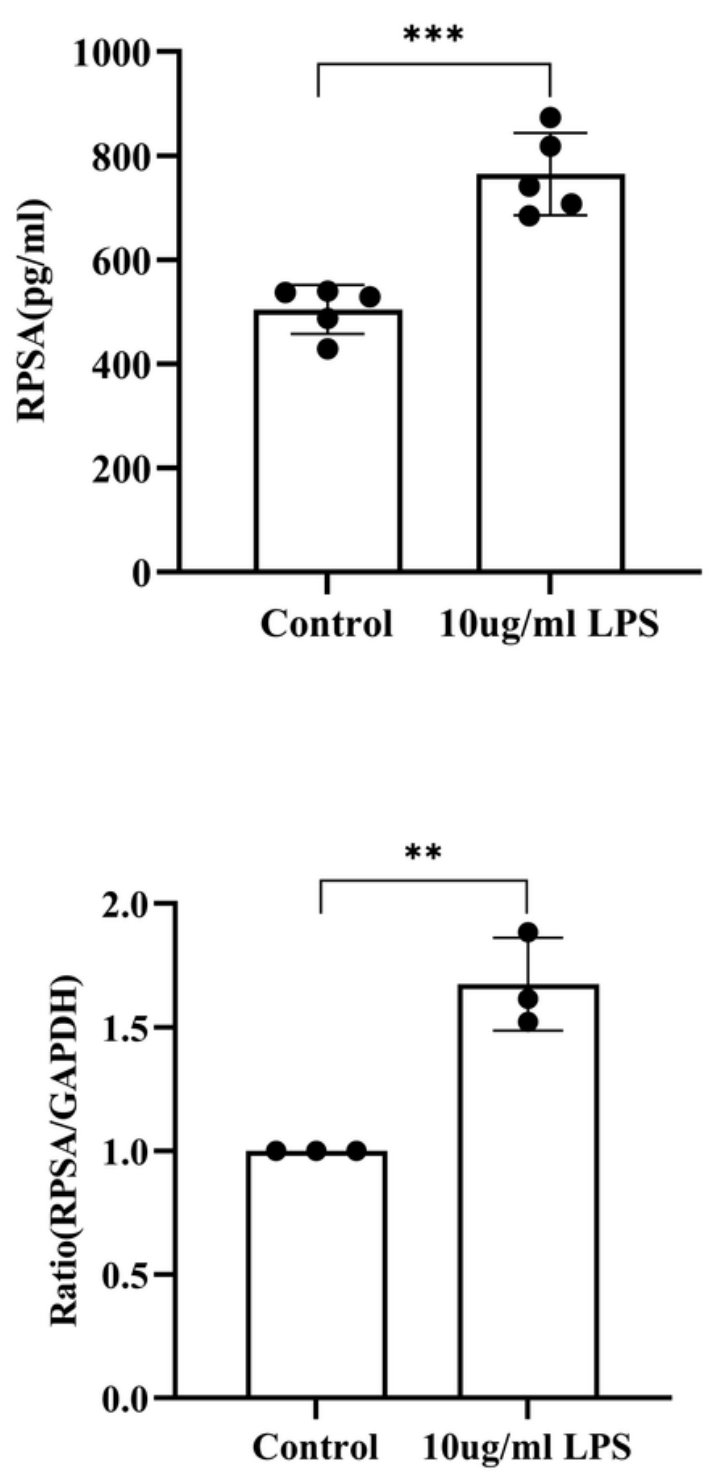

Figure 7

Validation of the expression levels of RPSA between Control group and $10 \mu \mathrm{g} / \mathrm{ml}$ LPS induced samples by qPCR (A), western blot (B), and ELISA (C) analysis. Control : Untreated cells. All data are presented as means $\pm S D$.

\section{Supplementary Files}

This is a list of supplementary files associated with this preprint. Click to download.

- SupplementaryFigure1.tif

- SupplementaryFigure2.tif 